\author{
Julián García Ramírez \\ Universidad de Medellín, Colombia \\ juliangarcia05@gmail.com
}

\title{
Algunas reflexiones sobre el estatuto epistemológico de la historia del derecho ${ }^{1}$
}

\begin{abstract}
The need to rethink the epistemological statute of the history of law takes us to the need to go back to three fundamental aspects: being the memory of jurists (and of law); being a special history of texts; and lastly, being a juridical discourse of essential importance in the orientation of its studies. From the perspective of this aspect in particular, there is an expectation to define the basic conditions that allow understanding the history of law as an autonomous discipline, without this meaning disregarding the need for an understanding of this discipline on an interdisciplinary level.
\end{abstract}

Key words: History of law, Juridical discourse, Law historian, Contemporary Latin America

\section{Introducción}

La vida sólo puede ser comprendida mirando hacia atrás pero ha de ser vivida mirando hacia el presente

Søren Kierkegaard

Como anotación preliminar, es conveniente apuntar que la preocupación por desentrañar el fundamento epistemológico de la historia del derecho, ha discurrido por dos senderos. El primero, "de indiferencia", estima que la discusión sobre el carácter científico de la historia del derecho es un asunto sin importancia y de escasa trascendencia dogmática. Por el contrario, un segundo

1 Este artículo es el resultado de la investigación cofinanciada por la Universidad de Medellín y el Instituto Tecnológico de Monterrey, denominada "El espacio-tiempo vital de la Historia del Derecho en la América Latina Contemporánea”. Investigadores principales: Andrés Botero Bernal (Universidad de Medellín) y Ramón Narváez (Instituto Tecnológico de Monterrey). 
sendero, "de esperanza", considera que la delimitación epistemológica de la historia del derecho es un asunto "sustancial para conocer las entrañas de la disciplina que nos ocupa [...]" (Martínez, 2003 : 384). Este trabajo aspira, concretamente, discurrir por el segundo sendero, es decir, justifica la necesidad de buscar la identidad de la historia del derecho tras la previa aproximación a su fundamento epistemológico.

Sin intención de resumir la importancia de la historia del derecho en la enunciación de simples ideas generales, bien puede afirmarse que su interés no se reduce a la presentación de algunos datos históricos que pudieron coadyuvar a la formación y al desarrollo del derecho mismo; por el contrario, su esencia se encuentra en la contextualización de esos diferentes momentos históricos que dotan al derecho. ${ }^{2}$ En ese sentido, la iushistoria, como disciplina autónoma, reconoce la diversidad del derecho en sus diferentes entornos de producción y, bajo ese mismo entendimiento, lo aprehende mediante fuentes directas sin proyectarlo indefinidamente hacia contextos en los que muy posiblemente asume una configuración completamente distinta. En palabras de Hespanha:

La segunda estrategia radica en la elección del derecho en sociedad como objeto de la historia jurídica. Esta línea de evolución, que domina la historiografía contemporánea a partir de la École des Annales, lleva a una historia del derecho íntimamente ligada a la de los diversos contextos (cultura, tradiciones literarias, estructuras

2 En ese sentido, la intención de asumir la comprensión del derecho en función de su espaciotiempo vital permite explicar el hecho de que la historia jurídica pretenda estudiar su objeto desde un enfoque relativo (contextual), es decir, la historia del derecho no mira la historia de esta disciplina (derecho) como una sucesión de momentos que permanecen inalterados y, por lo tanto, inamovibles con el transcurso del tiempo. Por el contrario, entiende que el derecho es un producto social: se desarrolla en un entorno social y, en consecuencia, su explicación y aprehensión debe efectuarse a partir de las herramientas que el medio provee al observador para su adecuado entendimiento (asunto que, al mismo tiempo, remite a la necesidad de apelar a las fuentes directas para encauzar los estudios del historiador del derecho, como conditio sine qua non para la credibilidad de los mismos). En igual sentido, es decir, resaltando la naturaleza esencialmente contextual del derecho, escribe Hespanha: "A história do direito realiza esta missão sublinhando que o direito existe sempre "em sociedade" (situado, localizado) e que, seja qual for modelo usado para descrever as suas relações com os contextos sociais (simbólicos, políticos, económicos, etc.), as soluções jurídicas são sempre contingentes em relação a um dado envolvimento (ou ambiente). São, nesse sentido, sempre locais" (Hespanha, 2005 : 21). "La historia del derecho realiza esta misión surayando que el derecho sólo es posible (situado, localizado) "en sociedad" e, independientemente del modelo usado para describir sus relaciones con los contextos sociales (simbólicos, políticos, económicos, etc.), las soluciones jurídicas son siempre contingentes en relación a determinado entorno (o ambiente). Siempre son, en este sentido, locales". La traducción de este acápite y las subsiguientes que se efectuarán, tienen como referencia la traducción de Isabel Soler y Concepción Valera (Hespanha, 2002 : 15). 
sociales, convicciones religiosas) con los cuales (y en los cuales) el derecho funciona (Hespanha, $2005: 21){ }^{3}$

De ese modo, pareciera que los diferentes estudios en historia del derecho comprendieran un interés implícito: la necesidad de conferir al derecho un adecuado tratamiento histórico a partir de la rigurosa comprensión del proceso jurídico analizado. En otras palabras, al historiador del derecho le interesa el dato jurídico (le interesa una parte del todo, sin que ello suponga, como es apenas natural considerarlo, el estricto y total desprendimiento del conjunto, es decir, del entorno social, mas no uno cualquiera, sino un entorno social que esté en relación con su objeto de estudio), le interesa, por lo tanto, valorar la esencia del derecho en su momento, empleando el lenguaje histórico correspondiente, develando el sentido propio de las instituciones y leyendo el pasado sin confundirlo (icontaminarlo?) con su presente. ${ }^{4}$

Esa forma de concebir la historia del derecho, como disciplina jurídica autónoma, conduce a la necesidad de interrogarse sobre las condiciones esenciales que determinan su estatuto epistemológico. En ese sentido, el discurso jurídico, la historia de textos y la conservación de la memoria del derecho, ${ }^{5}$ son aspectos que caracterizan la historia del derecho, permiten calificarla como una disciplina autónoma y, a su vez, diferenciarla de otras que también pudieren tener al derecho como centro de observación (es el caso de la historia general, la sociología jurídica, etc.). Sin embargo, mientras la "historia de textos" denota un aspecto metodológico y de "la memoria del jurista" se infiere la finalidad de la historia del derecho, el discurso iushistórico, por su parte, es un aspecto del que es posible inferir el fundamento epistemológico de la disciplina histórico jurídica.

3 "A segunda estratégia é a de eleger como objecto da história jurídica o direito em sociedade. Esta linha de evolução, que domina a historiografia contemporânea a partir da École des Annales (com sua idéia de uma "história total") leva a uma história do direito intimamente ligada à história dos diversos contextos (cultura, tradições literárias, estruturas sociais, convicções religiosas) com os quais (e nos quais) o direito funciona" (Hespanha, 2005 : 35).

$4 \mathrm{Al}$ respecto, merecen citarse las asertivas palabras de Fustel de Coulanges, referidas al modo de valorar la historia de Grecia y Roma: "Para conocer la verdad sobre estos antiguos pueblos es cuerdo estudiarlos sin pensar en nosotros, cual si nos fuesen perfectamente extraños; con idéntico desinterés y el espíritu tan libre como si estudiásemos la India antigua o la Arabia" (De Coulanges, 1997 : XII).

5 Ideas que son desarrolladas en diferentes artículos Botero Bernal, entre los cuales, el más enfático corresponde al libro inédito titulado "El derecho de los jueces antioqueños en la primera mitad del siglo XIX". Esa idea de la historia del derecho como memoria del jurista es suscrita, entre otros, por Rigoberto Ortiz Treviño (2006), quien estima que el oficio del iushistoriador se traduce en un diálogo dirigido a los juristas, es decir, "el historiador del derecho escribe para el jurista" . Por su parte, ha sido Carlos Petit (2005), profesor de la Universidad de Huelva, quien ha desarrollado con mayor profundidad lo concerniente a la hitoria del derecho como memoria jurídica. 
Por lo tanto, en nuestro sentir, la característica que mejor explica la naturaleza de la historia del derecho es el discurso jurídico: por medio del análisis del discurso iushistórico y, en particular, de sus elementos constitutivos, ${ }^{6}$ es posible:

i. Construir una forma de epistemología para la historia del derecho;

ii. Dotar de unidad (y al mismo tiempo, de identidad) a la disciplina histórica jurídica; y, finalmente,

iii. Enfrentar el problema de la interdisciplinariedad con previo reconocimiento de su propia autonomía.

Similares planteamientos serán desarrollados a lo largo del texto con la ayuda de algunos ejes temáticos que permitirán concentrar las ideas en forma ordenada, coherente y sistemática. En ese sentido, se empezará cualificando la función del iushistoriador con fundamento en su carácter discursivo; posteriormente, se hará mención a los elementos que integran el discurso iushistórico y a la forma de su asunción en el contexto latinoamericano; del mismo modo, entre líneas, se expondrán algunas reflexiones que volverán a la importancia del discurso en la formulación epistemológica de la disciplina iushistórica; y, finalmente, se presentarán algunas conclusiones que, en sustancia, no son más que otro comienzo para seguir debatiendo y fortaleciendo los brazos disciplinarios de la historia del derecho.

\section{Una aproximación al carácter discursivo de la función del iushistoriador}

Calificar la función del historiador del derecho como el producto de un esfuerzo discursivo, diferenciable de otra clase de apropiaciones del lenguaje, supone como presupuesto necesario la referencia a ese lugar común que orienta el análisis del iushistoriador y, del mismo modo, define la ontología que identifica la disciplina histórica jurídica. Se trata, por lo tanto, de cultivar el pasado del derecho, volverlo memoria del presente (Petit, 2005), aprehenderlo en su con-texto con el fin de ajustarlo a las condiciones que rodearon y moldearon la formación del mismo.

De esta forma, la función del historiador del derecho es esencialmente discursiva, ${ }^{7}$ bien porque en la aproximación a su objeto deba apelar al discurso como instrumento de cognición, o bien porque su actividad se presente bajo el formato de un discurso (científico en el mejor de los casos) (Petit, 2003), asistido de especiales intenciones comunicativas y, como es natural, orientado a producir

6 Entre ellos, el entorno, el destinatario, el emisario y su enunciado.

7 El discurso es uno de los elementos transversales en la formación de la disciplina iushistórica; es decir, el discurso iushistórico es la historia del derecho en movimiento. En palabras Andrés Botero Bernal: "Consideramos pues, que la historia del derecho es una disciplina jurídica caracterizada, esencialmente, por tres aspectos: es memoria del derecho y del jurista, es un particular discurso jurídico y es una historia de textos" (Botero, Inédito). 
una reacción en sus posibles destinatarios. En consecuencia, bien podría decirse que el iushistoriador es presa de un discurso fabricado o, en su caso, factor de su propio discurso; por lo tanto, siguiendo los rastros de Carlos Petit -de la Universidad de Huelva-, sería poco técnico afirmar que el objeto de la historia del derecho, y aún más reduccionista pensar que la función del iushistoriador, se concentran principalmente en el estudio del derecho presente o pasado; por el contrario, es decir, en estricto sentido, tanto la disciplina iushistórica como el historiador del derecho se preocupan por lo que han podido decir y escribir personas insertas en ciertas instituciones (es decir, por su discurso, bien oral o bien escrito). En sus palabras:

[...] la razón mejor que hoy justifica la presencia de la historia jurídica [...] se encuentra en el cultivo y desarrollo de la llamada memoria del jurista, expresión comprometida que entiendo, provisionalmente, como la tradición "disciplinar" del Derecho y de los que socialmente se identifican como sus expertos [...] en ese sentido, no sería el Derecho - presente o pasado- el principal objeto de observación, sino todo aquello que, a apropósito del Derecho, han podido decir y escribir personas insertas en ciertas instituciones (tribunales, universidades, parlamentos) encargadas de la producción de textos reputados como jurídicos (Petit, 2005 :237).

Sin embargo, a pesar de calificar la función del historiador del derecho como un ejercicio esencialmente discursivo, aún quedan por establecer las condiciones que permiten diferenciarlo, que no aislarlo, de otras formas discursivas que pudieran asimilársele. Con ese propósito, debe decirse que el historiador del derecho forja su discurso a partir de la selección de su objeto de estudio, es decir, de aquello que conmueve su interés y hacia lo cual debe dirigir su atención. En consecuencia, si al igual que la historia general, la historia del derecho se preocupa por regresar al pasado, la diferencia debe sentirse en que la segunda lo hace con ayuda del texto (como diría Petit, que se reputa jurídico) y sin alejarse de su contexto, esto es, de la lectura estrictamente jurídica que hace del mismo con el fin de acercar una realidad igualmente jurídica. ${ }^{8}$

Siendo el objeto de estudio lo que identifica el carácter jurídico del discurso y, al mismo tiempo, siendo el objeto parte esencial del discurso iushistórico, es

$8 \mathrm{Al}$ respecto, escribe Zorraquín Becú: “¿Cuál debe ser, entonces, el objeto de la disciplina históricojurídica? [...] debemos decir "historia de lo que fue derecho" o "historia de los sistemas jurídicos pasados". No estudiamos el derecho, sino hechos, que fueron derecho en su oportunidad, pero debemos contemplar esos hechos como integrantes de un sistema, aunque ese sistema haya dejado de serlo. Porque si lo contempláramos sólo como una sucesión de acontecimientos el conjunto perdería toda coherencia". Citado por: Vilches Fuentes (2005). 
posible inferir del discurso su función estructurante y, por lo tanto, constituyente; es decir, mediante el discurso del historiador del derecho puede, no sólo establecerse el objeto de la disciplina, sino también su método y, en algunos casos, la finalidad genérica que la identifica (estos es, la adecuada contextualización del derecho como proceso social e históricamente relevante). ${ }^{9}$

De líneas precedentes, por lo tanto, conviene resaltar la presencia de una relación entre el historiador del derecho, su discurso y las circunstancias materiales que caracterizan lo efectivamente dicho (tiempo, modo, lugar, tipo de enunciado); se trata, por tanto de factores coincidentes, que permiten advertir en la función del iushistoriador la asunción de un proceso específico de apropiación del lenguaje, esto es, de aquel que hace una lectura jurídica del pasado por mediación del texto y con sujeción a él. ${ }^{10}$

9 Del mismo modo, la determinación y el análisis detallado de los diferentes elementos que integran el discurso del historiador del derecho permite diferenciarlo de aquel discurso forjado por el historiador general, confiriéndole, de esa forma, la autonomía necesaria y, en consecuencia, facilitando las relaciones interdisciplinarias entre ambas esferas de conocimiento.

10 Debe indicarse que las discusiones en este campo y con relación a este tema no han sido pacíficas ni coincidentes: Aún no existe un acuerdo entre historiadores e historiadores del derecho (con alusión específica al caso latinoamericano) acerca de la condición epistemológica de la historiajurídica y de su función académica como disciplina autónoma. No obstante, por ser un enfoque que no compromete los intereses inmediatos del presente texto, se recomienda la lectura de un artículo que recoge las esencias de ese debate: Lecuona (2006). Más aún: no es pacífica la consideración de la iushistoria como una disciplina jurídica autónoma; algunos, afectos a la historia general (idebiéramos decir: generalizante?), estiman que la historia del derecho es un apéndice de la historia general, es decir, es una parte de ésta. Este asunto, de no pocas discusiones entre historiadores e historiadores del derecho, bien puede ilustrarse, de un modo general, con los pasajes que siguen: Entre los primeros merecen recordarse las palabras de Marc Bloch: "la enseñanza y el manual, que son admirables instrumentos de esclerosis, han vulgarizado el nombre (de aquella ciencia). Sin embargo, ¿qué recubre? Una regla de derecho es una norma social, explícitamente imperativa [...] En el sentido estricto de la palabra, el derecho es, pues, la envoltura de realidades en sí mismas demasiado variadas para suministrar con provecho el objeto de un estudio único y no agota ninguna de ellas [...] En suma, la historia del derecho podría no tener existencia aparte, como no fuera la historia de los juristas" (Bloch, 1965 : 115-116). Entre los segundos, por su parte, es preciso recordar las palabras de García-Gallo: "El Derecho es una ordenación de la vida social que posee fuerza vinculante. Es sólo una ordenación, no la vida social misma en toda su complejidad; esto independientemente de la importancia que aquélla pueda tener para ésta. El objeto de la ciencia de la Historia del Derecho debe limitarse sólo a aquella ordenación sin pretender abarcar la vida social, que en su conjunto o en sus particulares manifestaciones constituye el objeto de otras ciencias [...] El Derecho constituye, sin duda, un aspecto de la cultura global de la sociedad, pero con la suficiente entidad para poder ser objeto de estudio en sí mismo; como lo son también la religión, el lenguaje, el arte, etc." (García-Gallo, 1971: 17-18). Más recientemente, ha escrito Emilio Lecuona, profesor de la Universidad de Málaga: "Esta cuestión, que a priori parece sencilla de resolver, pues es evidente que la Historia del Derecho es una especialidad histórica es, sin embargo, una de las cuestiones que en general han sido más descuidadas por los historiadores del derecho, no sólo norteamericanos. El hecho de que la Historia Jurídica como disciplina claramente delimitada en la 
Considerada en esa forma, la función del iushistoriador se concreta en el discurso y se reduce al mismo. En el primer caso, desde una dimensión constituyente; en el segundo, por el contrario, desde una dimensión constitutiva. ${ }^{11}$ En consecuencia, si el discurso, a la vez que oral, puede ser escrito, deberá indicarse, respecto de la labor del historiador del derecho, que el uso lingüístico como instante de apropiación efectiva del lenguaje se presenta bajo el formato de un texto (bien oral o bien escrito) que identifica el producto de su función como la especial orientación de su disciplina. A partir de ese momento, es decir, desde el instante en que se interesa por acercar el pasado jurídico, empieza a explicitarse la conexión manifiesta entre el texto y la iushistoria (la historia del derecho, desde este enfoque, es una historia de textos, una experiencia discursiva) ${ }^{12}$ pero a su vez entre ésta y el contexto, aunque ya no de manera expresa sino latente, es decir, si bien no lo tiene como el eje central de sus análisis, tampoco se desprende de él en la consideración de los mismos: la historia del derecho, así descrita, es una historia que, sin desconocer el espacio-tiempo, proyecta el entorno jurídico desde la obra; es una historia de límites o bien, de posibilidades. Una historia, al fin, que circunscribe los esfuerzos

Contemporaneidad se haya desarrollado fundamentalmente por juristas en el entorno de la Ciencia del Derecho, ha provocado que éstos hayan siempre tratado de justificar su actividad para esta ciencia en lugar de para la histórica, de manera que por ejemplo se ha insistido constantemente en la utilidad de ella para los juristas e incluso se ha pedido su entrada en el currículo de los estudios de Derecho, mientras que se ha insistido poco o nada en su utilidad para los historiadores. Todo lo cual ha implicado un alejamiento general entre historiadores e historiadores del derecho que en países como Estados Unidos, donde se desarrolló en un primer momento una Historia Jurídica totalmente volcada a los juristas y a la práctica de los Tribunales, se convirtió, como ya se indicó anteriormente, en un auténtico abismo entre ellos" (Lecuona, 2006).

11 Constituyente por cuanto actúa como fuente de discurso, como enunciador o sujeto activo de la palabra. Constitutivo en tanto acude a prácticas discursivas establecidas que se integran a otro proceso igualmente discursivo, en esta ocasión, informándolo, es decir, no como fuente directa de discurso sino como referentes integrantes de otro (ejercicio discursivo).

$12 \mathrm{Al}$ respecto recuérdese lo dicho por Álvaro d'ors: "Así como la historia, en general, procede empezando por los más antiguo para acabar en lo actual, por analogía con la vida en general, lo más conveniente para el jurista que pretende hacer historia es seguir el método inverso, es decir, el de, partiendo del derecho actual, proceder retrospectivamente por los textos precedentes, hasta llegar a los orígenes" (d’Ors, 1999). Con similar intención, escribe el prof. Botero: el derecho pasado, lo que se reputó como tal, está condensado en los textos considerados como jurídicos, salvo, claro está, aquellos períodos donde el historiador del derecho debe auxiliarse de la arqueología y otras disciplinas ante la ausencia o estrechez de las fuentes escritas. El texto jurídico, así las cosas y a pesar de su vaguedad, es el objeto central, aunque no exclusivo dependiendo del caso, del análisis iushistórico, contextualizándolo y sin mediatizarlo. El texto, para la mayoría de los historiadores, es un medio de acercamiento a una realidad esquiva que se pretende atrapar. En cambio, para el iushistoriador el texto es, en principio, la realidad misma que desea hacer parte de la memoria colectiva de la disciplina (Botero, inédito). 
del iushistoriador en la aprehensión del con-texto y no en la reconstrucción del mismo. ${ }^{13}$

Por lo tanto, si el interés que subyace a los estudios iushistóricos es el de conferir identidad al amplio espectro jurídico, ${ }^{14}$ es necesario, previamente, dotar de identidad a la historia del derecho a partir del análisis del discurso del iushistoriador como agente receptor y/o productor del mismo. Es por esto que la historia del derecho debe proceder a un examen intradisciplinario que provea los suficientes elementos para asumir un sin número de interrogantes relacionados con su función discursiva, entre ellos: iquiénes hacen historia del derecho?, icuál es el margen de encuentro y cuál el de lejanía entre la iushistoria y la historia general?, icuáles son las condiciones metodológicas que identifican los estudios iushistóricos?, ¿cómo incide el contexto en la historia del derecho?, icómo acercarse al contexto en función de un estudio histórico jurídico? Inquietudes que sólo pueden responderse a partir del análisis de las diferentes condiciones en que se manifiesta, se aprehende o estructura el discurso iushistórico. ${ }^{15}$

Con fundamento en lo hasta ahora señalado, es posible destacar una segunda relación-complementaria a la descrita con precedencia: iushistoriador, discurso e información pragmática- ${ }^{16}$ integrada por el dato empírico del lenguaje (discurso) y la situación fáctica en que se desarrolla (contexto). Es en esa instancia de la

$13 \mathrm{Al}$ respecto debe precisarse que el discurso de quien hace historia del derecho, si bien no desconoce el contexto social de producción, se circunscribe esencialmente a ese conjunto de prácticas jurídicas que, dentro de ese entorno, trascienden a su estudio por la naturaleza de las mismas. Se asume, en este caso, lo que suele llamarse "el paradigma gallista" de la segunda fase, es decir, aquel que centra el interés en el dato jurídico sin desconocer la importancia, en algunas situaciones, del dato social. Al respecto, puede consultarse: Palma (2005).

14 Es así como el cometido de la historia del derecho es el de "conocer su pasado, para comprender el presente y proyectarse al futuro, dentro de un escenario científico-crítico de construcción de su memoria" (Botero, $2006: 14$ ).

$15 \mathrm{Al}$ respecto pudiera argüirse que resulta un contrasentido que sea la historia del derecho la que se provea a si misma las respuestas necesarias a cada una de las inquietudes relacionadas con su fundamentación epistemológica. Sin embargo, es igualmente cierto que delegar una responsabilidad de tal connotación a una disciplina diferente (por ejemplo, entregarla a la filosofía del derecho) supondría sacrificar la especialidad de la disciplina y, en un caso extremo, la autonomía de la misma. Ahora, si se asume como paradigma de estudio la interdisciplinariedad, es decir, la superación del paradigma fragmentario que dibujaba fronteras entre las ciencias para evitar su comunicación, se reconocerá con facilidad que el inconveniente inicialmente expuesto no reviste mayor trascendencia. En ese sentido, no habrá que mirar los saberes como parcelas aisladas sino como lugares compactos, pues al decir de Basarab (2007): "Disciplinarity, multidisciplinarity, interdisciplinarity and transdisciplinarity are four arrows for one and the same bow: the bow of knowledge" - "La disciplinariedad, la pluridisciplinariedad, la interdisciplinariedad y la transdisciplinariedad son las cuatro flechas de un solo y mismo arco: el del conocimiento".

16 Por información pragmática se alude a los diferentes elementos materiales que integran el discurso del historiador del derecho (destinatario, emisor, entorno, enunciado), cuya especial naturaleza permite diferenciarlos de cualquier uso indistinto, pero efectivo, del lenguaje. 
que se parte "del principio de que el uso lingüístico se da en un contexto, es parte del contexto" (Calsamiglia, et. al., 1999 : 17) y crea con-texto. En consecuencia, siendo la función del historiador del derecho un esfuerzo recreativo antes que creativo (como lo sería la del historiador general), ${ }^{17}$ es apropiado iterar que su fijación no es el contexto como sí el texto que le permite aproximarse a aquél; no quiere decir que el historiador del derecho deba desconocer ese conjunto de factores temporales y espaciales que ubican su estudio en épocas y lugares determinados; por el contrario, bien puede tenerlos en cuenta pero en proporción menor a aquellos que en realidad deben atraer su mirada. ${ }^{18}$ Esto, sin duda alguna, es una forma de decantar el discurso del historiador del derecho en cumplimiento de su función ${ }^{19}$, resumida con suficiente precisión en la sucinta frase de Álvaro d'Ors:

El historiador (extensivo al iushistoriador) no puede ir más allá de lo que permiten los textos conservados, y debe resignarse a practicar el "arte de ignorar", a diferencia del jurista, que debe construir

17 La labor del historiador del derecho es esencialmente recreativa, en la medida que su discurso se funda sobre la base de muchos otros, en función de los cuales aprehende un tiempo, un espacio y contextualiza su objeto de estudio. Por el contrario, si bien el historiador general puede recrear en el ejercicio de su profesión, el fundamento de su disciplina es la crear el contexto sin la limitación discursiva del historiador del derecho.

18 Otro aspecto de discusión entre el historiador del derecho y el historiador general es la mirada precisa del primero (calificada como reduccionista por los segundos) y el enfoque general de los segundos (considerado ambiguo por los primeros): esta disimilitud en la forma de emprender el análisis del objeto, es decir, desde lo general para el historiador o desde lo específico para el iushistoriador (es decir, con énfasis en el complejo jurídico), ha hecho que los resultados del primero sean tenidos por superficiales (con tenue profundidad), mientras los del segundo se califican de reduccionistas. Sin intención de fortalecer esa discusión, que más pareciera preocuparle el interés por resaltar equívocos desde un enfoque despectivo, debe indicarse que el esfuerzo de la iushistoria se representa en la preocupación por permitirle al derecho una identidad que se corresponda con las circunstancias específicas que circundan, condicionan y definen la orientación de los exámenes iushistóricos, que no es otra, como se ha dicho, que conferir identidad. Al respecto, escribe el profesor Botero Bernal: "[...] la memoria concede identidad. El conocer el pasado del fenómeno jurídico logra que éste adquiera identidad frente a otros hechos culturales, a la vez que permite entender su interrelación con los mismos" (Botero, 2006 : 16). En otras palabras, "la Historia del derecho, si estudia a éste como realidad técnica, peculiar, irreductible a cualquier otra, pero influida por los sectores de la sociedad más cercanos (lo político, lo cultural, lo económico) prestará un enfoque enriquecedor al entendimiento intelectual y profundo del derecho" (Tomás, et. al., 1979: 42). Para ser más claros: la lejanía entre la historia general y la historia del derecho, comúnmente está dada por el énfasis que se pone a los elementos compartidos por ambas disciplinas.

19 Se recomienda consultar el texto del profesor Víctor Uribe-Urán (2006), referente al constitucionalismo provincial colombiano, en el que se hace un uso adecuado del contexto general para ubicar el tema central de su estudio. 
soluciones congruentes para los casos no previstos en el derecho vigente (d'Ors, 1999 : 55).

Una frase que debe aceptarse en su rigor por aprehender la historia -y, para este caso, la historia del derecho- como una historia de textos (en esencia, como una historia del discurso histórico jurídico),${ }^{20}$ pero debiendo ser repensada en esa condición acrítica que pareciera adscribirle a la labor del iushistoriador y, en su contexto, a la del historiador. En cuanto a ese interés por asumir la historia del derecho (y la función del iushistoriador) como algo más que una unión cronológica de datos, ha escrito Paolo Grossi:

Creo firmemente que es una de las funciones, y desde luego no la última, del historiador del derecho la de ser conciencia crítica del estudioso del derecho positivo, descubriéndole su complejidad de aquello que en su visión unilateral puede parecerle simple, resquebrajando sus convicciones acríticas, relativizando certezas demasiado absolutas, insinuando dudas sobre lugares comunes aceptados sin una adecuada verificación cultural (Grossi, 2003). ${ }^{21}$

En conclusión, con fundamento en las ideas hasta ahora expuestas, cada una de ellas relacionadas o implicadas dentro del ejercicio discursivo del que es parte el historiador del derecho, es necesario reafirmar, por ser un elemento de suma trascendencia, los aspectos básicos que identifican la historia del derecho como disciplina autónoma y de estricta condición jurídica: el ser una historia esencialmente de textos (asumidos como jurídicos), el ser memoria del derecho como del jurista y, finalmente, el ser un discurso sustancialmente jurídico; aspecto último sobre el que seguirán discurriendo las siguientes líneas, por considerarlo el componente estructurante del conducto epistemológico que caracteriza la disciplina.

\section{Pensar la historia del derecho desde los componentes que cualifican el discurso iushistórico: condiciones para su asunción y desarrollo en la América Latina contemporánea}

La referencia al desarrollo de la historia del derecho en la América Latina contemporánea supone, por lo menos, la integración de dos aspectos que se infieren de esa formulación contextual de la disciplina: el primero, referente

20 Esto de por sí, identifica el discurso del historiador del derecho representado en un elemento material que integra la pragmática: la naturaleza y características del enunciado.

21 Este aspecto, concretamente, responde a una condición valorativa del discurso iushistórico, es decir, se ocupa de estipular la intención que debe fundamentar el discurso del historiador del derecho (en términos de Grossi: no basta una intención descriptiva; de igual manera, corresponde al historiador del derecho ser conciencia crítica del estudioso del derecho positivo). 
a la necesidad de edificar una identidad iushistórica a partir del conjunto de hechos, circunstancias o situaciones que cualifican el escenario latinoamericano en su trascendencia histórica como jurídica; el segundo, producto del anterior, orientado a conferir un manejo adecuado de la recepción de modelos extranjeros que aporten a una consciente elaboración de los estudios iushistóricos para América Latina. En ese sentido, el esfuerzo por aprehender la identidad de la historia del derecho en un espacio y un tiempo determinados depende del grado de sincronía que logre establecerse entre la adecuada apropiación de la cultura iushistórica de América Latina y la asunción de modelos foráneos ${ }^{22}$ que coadyuven a la suficiente comprensión de la misma. ${ }^{23}$

En ese sentido, será preciso unir el concepto de identidad (tan problemático en su esencia) con la idea de una América Latina que hace parte del derecho continental europeo (esto por la recepción del derecho común -ius communeen Latinoamérica) ${ }^{24}$ no con el fin de asumir una postura escéptica frente a la recepción, sino con la intención de reconocer la presencia de una realidad que debe mirarse (y en lo posible, sintetizarse) a partir de un enfoque necesariamente reflexivo; se trata, por lo tanto, de entender la recepción como un proceso crítico de asunción y concepción de algunas manifestaciones jurídicas o, como lo advierte Narváez:

La propuesta es la de crear en la ciencia jurídica una conciencia crítica que nos lleve a concebir el derecho en todos sus sentidos, a intuirlo en la problemática cotidiana, a descubrirlo en la sociedad y a entenderlo a través de su realidad histórica, política y conceptual (Narváez, 2003 : 18).

22 Se hace con esto referencia al desarrollo de un proceso de recepción, o bien de trascendencia -en términos de Ramón Narváez (2005) - suficientemente crítico y necesariamente reflexivo. El reconocimiento de los diferentes hechos que inciden en la historia del derecho latinoamericano, se relaciona profundamente con la necesidad de fortalecer el discurso iushistórico desde una dimensión constitutiva. En esta instancia, el historiador del derecho empieza a confeccionar un discurso sobre el discurso, es decir, encuentra un límite a su función: la porción de realidad que se ha propuesto analizar queda contenida en los contornos que identifican el texto jurídico apropiado; en otras palabras, queda atrapada en un discurso.

23 Para destacar la importancia del contexto como agente modulador de los estudios iushistóricos, baste citar, como ejemplo, la diferencia con que se asume el problema interdisciplinario entre la historia del derecho y la filosofía del derecho, según el contexto de formulación: en América Latina, en términos generales y por una condición más de los docentes que de las propias disciplinas, la historia del derecho y la iusfilosofía han compartido espacios comunes; en Europa, por el contrario, se tratan como dos continentes epistémicos con poca o ninguna relación interdisciplinaria.

24 "La supervivencia del derecho común en la doctrina americana, el conocimiento y manejo de sus fuentes por los codificadores americanos harían suponer una 'tercera vía del derecho romano'como la llama Martínez Martínez" (Narváez, 2003 : 9). Acerca de la "tercera vía del derecho romano" puede consultarse Martínez (2003). 
De esta forma, si se acoge la necesidad de pensar en una historia del derecho para América Latina (centrada en sus problemas e inquietudes), ${ }^{25}$ al mismo tiempo se estaría adjudicando la necesidad de indicar esos "lugares comunes" de los que partirán los estudios iushistóricos y en función de los cuales se forjaría el discurso del historiador del derecho. Un discurso con identidad, con autonomía, producto del consenso e indudable portador de algunas fuentes de información que permitan inferir otra serie de elementos que cualifican el saber histórico jurídico en su contexto latinoamericano; es decir, una vez formado el discurso del historiador del derecho, será posible, a través de él, ascender hasta la esencia de la disciplina para alcanzar la premisa de su identidad (con mayor exactitud, de su identidad en el contexto latinoamericano). ${ }^{26}$

Por lo tanto, si se ha sostenido que es posible cualificar el discurso del historiador del derecho mediante el análisis jurídico de los elementos que lo integran, asimismo es indispensable establecer la forma de hacerlo a partir del análisis de los factores extralingüísticos que lo caracterizan. En otras palabras, si la labor del historiador del derecho es esencialmente discursiva, esa forma de apropiación del lenguaje estará asistida, de igual manera, por una serie de elementos no lingüísticos que lo determinan. De ese modo, y con la mirada puesta en el discurso del historiador del derecho, esos factores permiten, en este caso, conferirle identidad (interna o externa), a ese conjunto de manifestaciones discursivas que tienen caracteres distintivos y, por supuesto, claramente diferenciables.

En ese sentido, el hecho de que el discurso iushistórico sea producto del historiador del derecho, que esté asistido por una intención comunicativa, que esa intención esté proyectada hacia un destinatario específico e inserta en un espacio-tiempo vital determinado (el mismo que se presenta al observador como una realidad jurídicamente aprehensible) permite efectuar un análisis detallado

25 Tendencia que tiempo atrás movió los intereses de algunos historiadores del derecho latinoamericanos, como ocurrió con Ricardo Levene, en el caso argentino, para quien el estudio de la historia del derecho argentino debía comprender, desde sus orígenes, "el estudio de los Derechos castellano, indígena, indiano y argentino propiamente dicho" (Levene, 1969 : 19). Esa misma línea sentada por Levene es seguida, entre otros, por Víctor Tau Anzoátegui y Eduardo Martiré, quienes justifican la continuidad de ese modelo no sólo "porque es el que hemos utilizado en la enseñanza, sino porque consideramos que su contenido está de acuerdo con la moderna concepción de la disciplina" (Anzoátegui, et. al., 1971).

26 Objetivo que se corresponde con el deseo central que impulsó el desarrollo del proyecto de Investigación: "El espacio-tiempo vital de la Historia del Derecho en la América Latina Contemporánea”, financiado por la Universidad de Medellín, en cuyo marco teórico se expresó: "Esa dependencia-carencia latinoamericana debe ser el motor que genere un venturoso proceso de superación de estos parámetros de sumisión, en busca de esa identidad que ceda espacios en términos de posibilidad a 'realizar la propia lectura-escritura', a asignarle un sentido y unos vínculos propios al quehacer del historiador del derecho latinoamericano". 
de los diferentes elementos que integran su discurso, y cuya interacción es posible advertir en el desarrollo del oficio del iushistoriador.

En consecuencia, si el discurso iushistórico subsume un conjunto de informaciones que permiten entender la historia del derecho en función de ese uso exclusivo del lenguaje, deberá advertirse, en primer lugar, que sólo corresponde al historiador del derecho la confección de ese discurso histórico jurídico; en otras palabras, sólo el iushistoriador podrá contextualizar el derecho en tiempos y espacios específicos, mediante el tratamiento adecuado de cada una de las instituciones jurídicas que se dispone analizar. Por tanto, a diferencia del historiador general, no le interesa el entono social en toda su extensión; sólo acudirá a su estudio si media alguna conexión directa con su objeto que facilite la necesaria aprehensión del mismo. ${ }^{27}$

En segundo lugar, el historiador del derecho fabrica su discurso para comunicarse, esencialmente, mas no exclusivamente, con otros académicos con similar formación en la disciplina iushistórica.

En tercer lugar, el discurso del historiador del derecho responde a una serie de condiciones temporales y espaciales que lo conducen y lo configuran. ${ }^{28}$ En otras palabras, y en este caso, se hace referencia a la necesidad de armonizar el discurso iushistórico con las diferentes inquietudes y quietudes históricojurídicas de la América Latina Contemporánea. Por lo tanto, al concentrar el discurso del historiador del derecho en la actual situación latinoamericana, se busca impulsar la formación de una identidad y una cultura jurídicas que permita contextualizar el derecho en un momento y un espacio determinados. Se trata,

27 De esto se sigue que el historiador, de frente al problema que lo ocupa, tiende a un empleo poco estricto de los términos jurídicos, pero a un uso más preciso de los términos sociales; asimismo, el historiador centra su estudio en las relaciones contextuales de una forma general (en donde el derecho funge como otra esfera de acción social que debe implicarse en ciertos fenómenos que explora), mientras el iushistoriador, puesto en ese marco de relaciones contextuales, fijará su atención en el estudio de aquello que comporta al derecho o que, al menos, suponga una invocación de lo jurídico, es decir, con trascendencia a él. Esto, sin embargo, no es un obstáculo para impulsar la integración disciplinaria entre la historia general y la historia del derecho que, en todo caso, debe ser una relación contingente, es decir, definida instancia del objeto de conocimiento.

28 El discurso del historiador del derecho (desde la óptica que se propone: la historia del derecho en la América Latina contemporánea) supone la conjunción de dos espacios-tiempos vitales que se relacionan sin confundirse. El primero, modelador de su discurso, es decir, contextualizador del mismo, funge como objeto de conocimiento al que se aproxima el historiador del derecho (qué estudiar). El segundo, de carácter externo, estará identificado por las condiciones mínimas que deben cualificar los estudios de la historia del derecho en la América Latina contemporánea (cómo estudiarlo). En otras palabras, uno es el espacio tiempo actual y otro, sustancialmente diferente, es el espacio tiempo que estudia el historiador del derecho y el cual va ínsito en su discurso. 
por lo tanto, de adscribir al discurso iushistórico una función configurante de la historia del derecho en la región. ${ }^{29}$

Finalmente, el discurso del historiador del derecho debe valerse de un enunciado que lo identifique $y$, al mismo tiempo, lo diferencie de otras formas discursivas que, desde enfoques disímiles, asumen el estudio del derecho aunque de forma fragmentaria, parcial y en no pocos casos, ausente del suficiente rigor jurídico. Por lo tanto, el discurso iushistórico -y en especial, el discurso jurídico latinoamericano- deben prestar su atención al dato estrictamente jurídico que subyace a su objeto de estudio. De ninguna manera, la propuesta por una historia del derecho edificada sobre la base de un discurso esencialmente jurídico afecta las relaciones con otras disciplinas; por el contrario, sólo a partir del reconocimiento de su autonomía y de su especial configuración -como se ha venido sosteniendo-, es posible establecer escenarios de diálogo y comunicación entre los diferentes saberes que pudieren resultar involucrados. En palabras de Botero Bernal:

Esto lleva a explicitar el segundo pilar del que parte la concepción de historia del derecho que no es otro que concebirla como un discurso jurídico. Esto es que la memoria que se haga debe ser lo más jurídica posible, puesto que se parte de una concepción de que la iushistoria es, ante todo, derecho dialogado y no historia profesional especializada. No se quiere de esta manera cerrar la posibilidad de una interdisciplinariedad, máxime que con la historia profesional se comparten no pocos aspectos metodológicos y conceptuales, pero un requisito sine qua non de la interdisciplinariedad es la existencia previa de disciplinas, esto es, de discursos científicos que quieran dialogar entre sí con respeto mutuo (Botero, inédito).

Habiendo expuesto la importancia del discurso para formular una fundamentación epistemológica de la historia del derecho y, en particular, de la historia del derecho en la América Latina contemporánea, resta indicar que las demás cualidades que identifican la historia del derecho, al lado del discurso jurídico, a saber: (i) el ser una memoria del derecho como del jurista y (ii) el ser una historia de textos (deberá agregarse, reputados como jurídicos), representan características que denotan, la primera, una propuesta para asumir

29 En otras palabras, se trata de hacer de la historia del derecho un discurso portador de la identidad de la disciplina jurídica en el actual contexto latinoamericano. En ese sentido, por lo tanto, la historia del derecho debe centrar su interés en las preocupaciones iushistóricas de su entorno (el latinomericano), con el fin de emprender una cultura jurídica que defienda la adecuada asunción del derecho en tiempos y espacios pretéritos. Del mismo modo, es responsabilidad del historiador del derecho regresar al pasado, ayudado de esenciales herramientas jurídicas (el texto reputado jurídico), con el vivo interés por mirar al derecho como un producto social, dinámico y, en consecuencia, fundamentalmente histórico - jurídico. 
la historia del derecho a efectos de distinguirla de la historia especializada; la segunda, una necesidad metodológica que garantiza la credibilidad a los estudios emprendidos por el historiador del derecho. Por su parte, el discurso jurídico, considerado elemento nuclear en la concreción disciplinaria de la historia del derecho, no sólo conjuga una serie de componentes que permiten conferir identidad a la iushistoria sino que, del mismo modo, su análisis proyecta la fuente epistemológica de la disciplina.

Finalmente, la importancia del discurso jurídico, adicionando lo hasta ahora expuesto, se manifiesta asimismo en el cumplimiento de una función limitativa; es decir, el historiador del derecho en el desarrollo de sus estudios está atrapado por el discurso que fue, el que ahora aprehende y del que no podrá desprenderse sin desbordar los cauces de la historia del derecho. Por lo tanto, la historia del derecho, pensada desde del discurso iushistórico, se presenta como una forma de historiografía jurídica que nace en el texto y muere en el mismo; en esencia, se presenta como un discurso sobre el discurso. ${ }^{30}$

\section{Reflexiones conclusivas}

El historiador, y menos aún el historiador del derecho, ni es un contador de granos de polvo despositados sobre el asfalto del pasado ni un embalsamador de cadáveres.

Paolo Grossi

Con el fin de resumir en algunas frases la importancia del discurso (jurídico) en la fundamentación epistemológica de la historia del derecho, bien puede decirse que éste es un proyecto que dota de identidad a la disciplina históricojurídica y, asimismo, le concede autonomía respecto de otros saberes que informan su independencia o defienden su sumisión. Por lo tanto, desde el discurso jurídico, además de abstraer las condiciones necesarias para defender la autonomía de la historia del derecho, es posible, simultáneamente, fortalecer la comunicación interdisciplinaria y la mutua implicación entre saberes científicos.

En ese mismo sentido, el discurso iushistórico se asocia y se expresa en espacios y tiempos que lo inciden, lo conducen y lo contienen. En el primer caso (al asociarse), el historiador del derecho se acerca a un discurso para aproximarse al pasado jurídico, es decir, a su objeto de estudio. En el segundo (cuando se

30 La propiedad semántica de la expresión tienta a considerar la historia del derecho como una forma de historiografía jurídica. Al respecto, el diccionario de la Real Academia de la Lengua Española define la historiografía como el estudio bibliográfico y crítico de los escritos sobre historia y sus fuentes, y de los autores que han tratado de estas materias. Por tanto, precisado el sentido de la palabra, ino podrá asumirse la historia del derecho como una forma de historiografía jurídica? 
expresa), por su lado, se vale de su discurso para fortalecer la cultura iushistórica de un entorno específico, de un espacio determinado y de un tiempo definido; en esencia, lo hace para hablar del pasado con la cultura jurídica de su presente.

En esa medida, el discurso del historiador del derecho es un aspecto modelador de los estudios iushistóricos desde el cual es posible, pensable y necesario edificar la estructura epistemológica de la disciplina histórico jurídica.

Por lo tanto, haciendo nuestras las palabras de Faustino Martínez, las breves reflexiones que hemos presentado sobre el estatuto epistemológico de la historia del derecho:

[...] en ningún caso son inamovibles, están sujetas a constante revisión por nuestra historiografía (rectificando posiciones personales, reflexionando o ampliando el campo de comprensión, añadiendo nuevos datos, etc.), en un intento por desentrañar lo que recientemente se han denominado los caminos de la ciencia jurídica (Martínez, 2003 : 384-385).

\section{Referencias}

Bloch, M. (1965). Introducción a la Historia. México: Breviarios del Fondo de Cultura Económica.

Botero Bernal, A. (inédito). El derecho de los jueces antioqueños en la primera mitad del siglo XIX. Texto inédito.

, (2006). "Presentación del libro", en: Botero Bernal, A. (Editor) Origen del Constitucionalismo Colombiano: Ponencias del III Seminario Internacional de Teoría General del Derecho. Medellín: Editorial Universidad de Medellín.

, (Editor) (2004). Naturaleza y cultura: una mirada interdisciplinaria. Medellín: Editorial Biogénesis.

, (2004). "Nuevos paradigmas científicos y su incidencia en la investigación jurídica”, Diritto e questioni pubbliche. Obtenido en septiembre de 2007, en : www.dirittoequestionipubbliche.org/D_Q-4/studi.htm.

, (2003). "La metodología documental en la investigación jurídica: alcances y perspectivas", Opinión jurídica, No. 4. p.p. 109- 116.

Calsamiglia Blancafort, H. y Tusoón Valls, A. (1999). "El análisis del discurso", Las cosas del decir. Manual de análisis del discurso. Barcelona: Ariel. 
Caraveo, L. M. (1991). "Una visión sobre la Interdisciplinariedad y su Construcción en los Currículos Profesionales", Revista de Ciencias Sociales y Humanidades, No. 5-6.

d’Ors, Á. (1999). Nueva introducción al estudio del derecho. Madrid: Civitas.

De Coulanges, F. (1997). La Ciudad Antigua. Bogotá: Panamericana.

García-Gallo, A. (1971). Metodología de la Historia del Derecho Indiano. Santiago de Chile: Editorial Jurídica de Chile.

Grossi, P. (2003). Mitología Jurídica de la Modernidad. Madrid: Trotta.

Hespanha, A. M. (2005). Cultura Jurídica Européia: síntese de um Milênio. Florianópolis: Fundação Boiteux.

Tecnos.

(2002). Cultura Jurídica Europea: Síntesis de un milenio. Madrid:

Florianópolis: Fundação Boiteux.

Lecuona, E. (2006). "Historia del derecho y ciencia jurídica en los Estados Unidos de América: el debate en torno al historicismo crítico de Robert W. Gordon", Revista de estudios histórico-jurídicos, No. 28. Obtenida en junio de 2007, en: <http://www.scielo.cl/scielo.php?script=sci_arttext\&pid=S0716$54552006000100018 \& \operatorname{lng}=\mathrm{es} \& \mathrm{nrm}=$ iso $>$.

Levene, R. (1969). Manual de historia del derecho argentino. Buenos Aires: Ediciones Depalma.

Martínez y Martínez, F. (2003). "Acerca de la recepción del ius commune en el derecho de indias: notas sobre las opiniones de los juristas indianos", Anuario Mexicano de Historia del Derecho, No. XV, p.p. 447-523.

Narváez Hernández, J. R. (2003). "Recibir y concebir el derecho en la historia: una propuesta a la base de la función de la historia del derecho", Revista Telemática de Filosofía del Derecho, No. 7, septiembre 2004.

Palma, E. E. (2005). "Papel de la cátedra de historia del derecho en la enseñanza Jurídica”, en: Palma, E. E., Historia del Derecho I. Santiago de Chile: Universidad Central de Chile.

Petit, C. (2005). "De la historia a la memoria. A propósito de la una reciente obra de historia universitaria", Cuadernos del Instituto Antonio de Nebrija de Historia de la Universidad, No. 8, p.p. 237-279. 
Tau Anzoátegui, V. y Mrtiré, E. (1971). Manual de Historia de las Instituciones Argentinas. Buenos Aires: Ediciones Macchi.

Tomás y Valiente, F. (1979). "La historiografía jurídica en la Europa continental (1900-1975)". LXXV años de evolución jurídica en el mundo: historia del derecho y derecho comparado. Volumen II. México: UNAM.

Universidad de León. (2007). Realización del 8o Congreso ISKO- España, León. Obtenido en marzo de 2007, en: www3.unileon.es/dp/abd/ISKO2007.pdf .

Uribe-Urán, V. (2006). "Constitucionalismo provincial colombiano, vida pública y vida privada en el período postcolonial”, en: Botero Bernal, A. (Editor), Origen del Constitucionalismo Colombiano: Ponencias del III Seminario Internacional de Teoría General del Derecho, No. 1.

Vilches Fuentes, H. (2005). "La teoría de la historia del derecho en Ricardo Zorraquín Becú", Revista de Estudios histórico-jurídicos, No. 27. Obtenido en julio 2006, en: <http://scielo-test.conicyt.cl/scielo.php?script $=$ sci_ arttext\&pid $=$ S0716-54552005000100017\&lng $=$ pt\&nrm $=$ iso $>$.

Von Der Becke, C. (2007). Glosario. Obtenido en abril de 2006, en: http://club. telepolis.com/ohcop/pragmati.html. 